\title{
PENINGKATAN KOMPETENSI SUPERVISI KEPALA SEKOLAH MELALUI SUPERVISI KELOMPOK DI SEKOLAH DASAR
}

\author{
Suryantini \\ UPTD Dikpora Kecamatan Banjarsari Surakarta \\ Suryantini1958@gmail.com
}

\begin{abstract}
The research is aimed to: 1) describe the process of managerial supervision using group technique to improve the principals' supervisory competence; and 2) imrove the principals'supervisory competence at Gugus II Bima UPTD Dikpora Kecamatan Serengan of Surakarta academic year 2012/2013 through managerial supervision using group technique.The type of the research is an action research. The research was done at Gugus II Bima UPTD Dikpora Kecamatan Serengan of Surakarta. The subjects of the research were 6 principals at Gugus II Bima UPTD Dikpora Kecamatan Serengan of Surakarta. The data collecting techniques were done using observation, interview and document techniques. The data analysis technique was done using Kemmis and Taggart model.The research concludes that: 1) the managerial supervision processes were done in three stages, namely: initial stage, observation stage, and feed-back stage; and 2) the managerial supervision using group technique is effective in improving the principals' supervisory competence at Gugus II Bima UPTD Dikpora Kecamatan Serengan of Surakarta academic year 2012/2013. It is demonstrated by the score improvement in each cycles.
\end{abstract}

Keywords: managerial supervision, group technique, principals' supervisory competence

\begin{abstract}
ABSTRAK
Penelitian ini bertujuan untuk: 1) mendeskripsikan proses pelaksanaan supervisi kelompok guna meningkatkan kompetensi supervisi bagi Kepala SD; dan 2) meningkatkan kompetensi supervisi bagi Kepala SD di Gugus II Bima UPTD Dikpora Kecamatan Serengan Kota Surakarta tahun pelajaran 2012/2013 melalui supervisi kelompok. Jenis penelitian adalah Penelitian Tindakan. Penelitian dilakukan di di Gugus II Bima UPTD Dikpora Kecamatan Serengan Kota Surakarta tahun pelajaran 2012/2013. Subyek penelitian ini adalah Kepala SD di Gugus II Bima UPTD Dikpora Kecamatan Serengan Kota Surakarta tahun pelajaran 2012/2013 dengan jumlah 6 orang Kepala Sekolah. Teknik pengumpulan data dilakukan dengan teknik dokumen, wawancara dan observasi. Teknik analisis data dilakukan dengan menggunakan model alur dari Kemmis dan Taggart. Hasil penelitian menyimpulkan bahwa: 1) Proses pelaksanaan supervisi supervisi manajerial dilakukan melalui prosedur
\end{abstract}


berbentuk siklus yang terdiri dari tiga tahap yaitu: tahap pertemuan pendahuluan, tahap pengamatan dan tahap pertemuan balikan; dan 2) Penerapan supervisi manajerial metode kelompok efektif dalam meningkatkan kompetensi supervisi kepala sekolah di Gugus II Bima UPTD Dikpora Kecamatan Serengan Kota Surakarta tahun pelajaran 2012/2013. Hal ini ditunjukkan dengan hasil penilaian yang mengalami peningkatan pada setiap siklus tindakan yang dilakukan.

Kata kunci: supervisi manajerial, metode kelompok, kompetensi supervisi kepala sekolah

\section{PENDAHULUAN}

Salah satu tugas pokok pengawas sekolah/satuan pendidikan adalah melakukan penilaian dan pembinaan dengan melaksanakan fungsi-fungsi supervisi, baik supervisi akademik maupun supervisi manajerial. Mengacu pada SK Menpan nomor 118 tahun 1996 tentang jabatan fungsional pengawas dan angka kreditnya, Keputusan bersama Mendikbud nomor 03420/O/1996 dan Kepala Badan Administrasi Kepegawaian Negara nomor 38 tahun 1996 tentang petunjuk pelaksanaan jabatan fungsional pengawas serta Keputusan Mendikbud nomor 020/U/1998 tentang petunjuk teknis pelaksanaan jabatan fungsional pengawas sekolah dan angka kreditnya, dapat dikemukakan tentang tugas pokok dan tanggung jawab pengawas sekolah yang meliputi: 1) Melaksanakan pengawasan penyelenggaraan pendidikan di sekolah sesuai dengan penugasannya pada TK, SD, SLB, SLTP dan SLTA; dan 2) Meningkatkan kualitas proses belajar-mengajar/bimbingan dan hasil prestasi belajar/bimbingan siswa dalam rangka mencapai tujuan pendidikan.

Diterbitkannya Peraturan Menteri Pendidikan Nasional Nomor 13 Tahun 2007 tentang Standar Kepala Sekolah/Madrasah, mengandung implikasi logis bahwa kepala sekolah sebagai pimpinan tertinggi di sekolah dituntut memiliki lima dimensi kompetensi, yaitu dimensi-dimensi kompetensi kepribadian, manajerial, kewirausahaan, supervisi, dan sosial. Operasionalisasi PP Nomor 13 tahun 2007 tersebut diatur melalui Peraturan Menteri Pendidikan Nasional Nomor 28 Tahun 2010 tentang Penugasan Guru sebagai Kepala Sekolah/ Madrasah yang menguraikan syarat-syarat dan tahapan yang harus dilalui seorang guru untuk dapat diberi tugas tambahan sebagai kepala sekolah/madrasah (Kemdiknas, 2011).

Kenyataan di lapangan menunjukkan bahwa tidak semua kepala sekolah memiliki kompetensi sesuai dengan ketentuan tersebut di atas. Hal yang sama juga terjadi di Gugus II Bima UPTD Kecamatan Serengan Kota Surakarta.

Kompetensi supervisi yang harus dimiliki oleh kepala sekolah setidaknya mencakup (1) merencanakan program supervisi akademik dalam rangka peningkatan profesionalisme guru (2) melaksanakan supervisi akademik terhadap guru dengan menggunakan pendekatan dan tehnik supervisi yang tepat (3) menindaklanjuti hasil supervisi akademis terhadap guru dalam rangka peningkatan profesionalisme guru (Depdiknas, 2007: 228).

Dalam kenyataannya, ternyata dari 6 (enam) orang kepala SD/ SDLB yang ada di Gugus II Bima UPTD Kecamatan Serengan Kota Surakarta tidak semuanya melakukan ketiga komponen supervisi tersebut di atas. Ada kepala sekolah yang sama sekali tidak mempunyai program supervisi, ada pula yang sudah mempunyai program supervisi namun tidak 
melaksanakan supervisi. Ada pula yang sudah mempunyai program dan sudah melaksanakan supervisi tetapi ternyata tidak melaksanakan tindak lanjut program supervisi yang sudah dilaksanakan. Hal ini berdampak pada kurang optimalnya kinerja guru dalam pembelajaran.

Kondisi semacam itu perlu dibenahi agar kinerja guru menjadi lebih optimal. Salah satu upaya yang dilakukan adalah dengan melaksanakan pembinaan melalui kegiatan supervisi kelompok bagi kepala sekolah.

Menurut Pidarta (2009: 12) dijelaskan bahwa teknik supervisi kelompok adalah suatu pembinaan terhadap sejumlah guru/ Kepala Sekolah oleh satu atau beberapa supervisor. Dalam supervisi kelompok ini dihidangkan suatu materi atau sekelompok materi kepada sekelompok guru yang mengikuti supervisi. Materi tersebut diterima bersama, dibahas bersama, dan disimpulkan bersama. Semua dilakukan di bawah asuhan supervisor, jadi dalam waktu yang tidak terlalu lama dapat dibina sejumlah guru.

Supervisi merupakan suatu kegiatan yang dirancang secara khusus untuk membantu para guru dan supervisor dalam. mempelajari tugas mereka. Hal ini dikemukakan oleh Sergiovani dan Starrat (Purwanto, 2003: 72) menyatakan bahwa "Supervision is a process designed to help teacher and supervisor learn more about their practice; to better able to use their knowledge and skills to better serve parents and schools; and to make the school a more effective learning community".

Supervisi dilakukan oleh kepala sekolah. Salah satu peranan Kepala Sekolah adalah sebagai Supervisor. Tugas sebagai supervisor adalah mensupervisi pekerjaan yang dilakukan oleh tenaga kependidikan. Supervisi merupakan suatu proses yang dirancang secara khusus untuk membantu para guru dan supervisor dalam mepelajari tugas sehari-hari di sekolah; agar dapat menggunakan pengetahuan dan kemampuannya untuk memberikan layanan yang lebih baik pada orang tua peserta didik dan sekolah, serta berupaya menjadikan sekolah sebagai masyarakat belajar yang lebih efektif (Mulyasa, 2005: 72).

Berdasarkan pengertian di atas, maka supervisi adalah suatu kegiatan yang dilaksanakan oleh kepala sekolah untuk membantu para guru dan supervisor dalam mepelajari tugas seharihari di sekolah; agar dapat menggunakan pengetahuan dan kemampuannya untuk memberikan layanan yang lebih baik pada orang tua peserta didik dan sekolah, serta berupaya menjadikan sekolah sebagai masyarakat belajar yang lebih efektif.

Menurut Pidarta (2009: 12) dijelaskan bahwa teknik supervisi kelompok adalah suatu pembinaan terhadap sejumlah guru oleh satu atau beberapa supervisor. Dalam supervisi kelompok ini dihidangkan suatu materi atau sekelompok materi kepada sekelompok guru yang mengikuti supervisi.

Materi tersebut diterima bersama, dibahas bersama, dan disimpulkan bersama. Semua dilakukan di bawah asuhan supervisor, jadi dalam waktu yang tidak terlalu lama dapat dibina sejumlah guru. Berdasarkan pengertian tersebut, maka dapat disimpulkan bahwa teknik supervisi kelompok adalah suatu pembinaan terhadap sejumlah guru oleh satu atau beberapa supervisor, yang dilaksanakan bersama-sama oleh supervisor dengan sejumlah guru dalam satu kelompok.

Berdasarkan latar belakang tersebut di atas, maka tujuan penelitian tindakan ini adalah sebagai berikut: 1) Untuk mengetahui proses pelaksanaan supervisi kelompok guna meningkatkan kompetensi supervisi bagi Kepala SD; dan 2) meningkatkan kompetensi 
supervisi bagi Kepala SD di Gugus II Bima UPTD Dikpora Kecamatan Serengan Kota Surakarta tahun pelajaran 2012/2013 melalui supervisi kelompok.

\section{METODE}

Penelitian dilakukan di Gugus II Bima UPTD Dikpora Kecamatan Serengan Kota Surakarta. Subjek dalam penelitian ini adalah kepala Sekolah Dasar di Gugus II Bima UPTD Dikpora Kecamatan Serengan Kota Surakarta tahun pelajaran 2012/2013 dengan jumlah 6 orang kepala sekolah. Penelitian dilakukan selama 3 (tiga) bulan, yaitu dimulai pada minggu I bulan September 2012 hingga minggu II bulan Nopember 2012.

Penelitian dilakukan dengan dua siklus tindakan. Setiap siklus diakhiri dengan tahapan refleksi. Data yang diperoleh dianalisis dan dimaknai dengan menggunakan analisis deskriptif prosentase dan untuk mengetahui perubahan hasil tindakan dilakukan dengan membandingkan hasil supervisi pada tindakan siklus sebelumnya.

Teknik pengambilan data dilakukan dengan cara observasi, wawancara, dan analisis dokumen. Observasi dilakukan terhadap praktek pelaksanaan pembelajaran yang dilakukan kepala sekolah dengan tiga indikator yang meliputi: a) penyusunan program supervisi, b) pelaksanaan supervisi, dan c) pelaksanaan tindak lanjut supervisi. Wawancara dilakukan sebelum dan sesudah berlangsungnya kegiatan pembelajaran.

Prosedur analisisnya menggunakan model alur dari Kemmis dan Taggart yang intinya mengidentifikasi perkembangan dan perubahan subjek setelah subjek diberi perlakuan khusus atau dikondisikan pada situasi tertentu dengan tindakan dalam kurun waktu tertentu dan berulang-ulang sampai program dinyatakan berhasil.

\section{HASIL DAN PEMBAHASAN}

Data kondisi awal kompetensi kepala sekolah dalam supervisi diperoleh melalui pengamatan yang dilakukan terhadap tiga tahapan supervisi. Ketiga tahapan tersebut mencakup aspek perencanaan, aspek pelaksanaan, dan aspek tindak lanjut supervisi. Hasil pengamatan yang dilakukan sebelum dilaksanakannya program supervisi manajerial dengan metode kelompok dapat disajikan ke dalam tabel berikut.

Tabel 1

Hasil Penilaian 1 Kompetensi Supervisi Kepala Sekolah Kondisi Awal

\begin{tabular}{|c|c|c|c|c|c|}
\hline \multirow{2}{*}{ No. } & \multirow{2}{*}{$\begin{array}{l}\text { Inisial } \\
\text { Subjek }\end{array}$} & \multicolumn{2}{|c|}{ Skor } & \multirow{2}{*}{ Ketercapaian \% } & \multirow{2}{*}{ Keterangan } \\
\hline & & Ideal & Riil & & \\
\hline 1. & YAH & 40 & 22 & $55.00 \%$ & Kurang \\
\hline 2. & UHA & 40 & 9 & $22.50 \%$ & Sangat Kurang \\
\hline 3. & SUP & 40 & 20 & $50.00 \%$ & Kurang \\
\hline 4. & NAR & 40 & 0 & $0.00 \%$ & Sangat Kurang \\
\hline 5. & SUM & 40 & 29 & $72.50 \%$ & Cukup Baik \\
\hline 6. & CIP & 40 & 0 & $0.00 \%$ & Sangat Kurang \\
\hline
\end{tabular}

Data tingkat kompetensi supervisi kepala sekolah di Gugus II Bima UPTD Dikpora Kecamatan Serengan pada kondisi awal dapat disajikan ke dalam diagram sebagai berikut: 


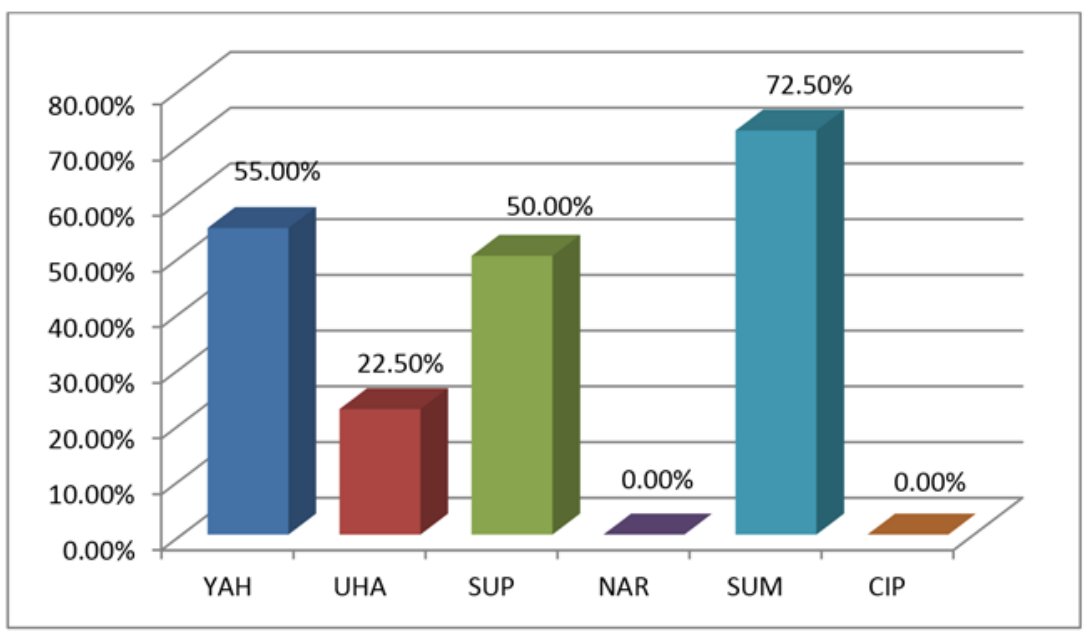

Gambar 1 Diagram Kompetensi Supervisi Kepala Sekolah Kondisi Awal

Hasil-hasil penilaian awal sebagaimana disajikan di atas memberikan gambaran bahwa dari 6 kepala sekolah yang ada, ada 2 orang (33.33\%) yang belum menyusun rencana program supervisi, belum melaksanakan, dan belum melaksanakan tindak lanjut supervisi. Satu orang kepala sekolah (16.67\%) sudah menyusun rencana program supervisi, tetapi belum melaksanakan supervisi dan belum melaksanakan program tindak lanjut. Dua orang kepala sekolah (33.33\%) sudah menyusun rencana supervisi dan sudah melaksanakan kegiatan supervisi tetapi belum melaksanakan program tindak lanjut supervisi. Satu orang kepala sekolah (16.67\%) sudah menyusun rencana kegiatan supervisi, sudah melaksanakan supervisi dan sudah melaksanakan program kegiatan tindak lanjut supervisi.

Melihat kondisi semacam itu, pengawas sekolah sebagai supervisor perlu melakukan tindakan untuk melakukan pembinaan. Tindakan yang dilakukan adalah melaksanakan kegiatan supervisi manajerial melalui supervisi kelompok di Gugus II Bima. Tindakan supervisi kelompok yang dilakukan adalah pembimbingan dengan materi penyusunan perencanaan program supervisi, pelaksanaan supervisi, kegiatan tindak lanjut supervisi. Pendekatan yang digunakan adalah metode supervisi kelompok dengan teknik direktif.

Hasil pengamatan yang dilakukan setelah dilaksanakannya program supervisi manajerial dengan metode kelompok pada tindakan Siklus I dapat disajikan ke dalam tabel berikut.

Tabel 2

Hasil Penilaian Kompetensi Supervisi Kepala Sekolah Tindakan Siklus I

\begin{tabular}{|c|c|c|c|c|c|}
\hline \multirow{2}{*}{ No. } & \multirow{2}{*}{$\begin{array}{l}\text { Inisial } \\
\text { Subjek }\end{array}$} & \multicolumn{2}{|c|}{ Skor } & \multirow{2}{*}{ Ketercapaian \% } & \multirow{2}{*}{ Keterangan } \\
\hline & & Ideal & Riil & & \\
\hline 1. & YAH & 40 & 28 & $70.00 \%$ & Cukup Baik \\
\hline 2. & UHA & 40 & 18 & $45.00 \%$ & Sangat Kurang \\
\hline 3. & SUP & 40 & 29 & $72.50 \%$ & Cukup Baik \\
\hline 4. & NAR & 40 & 9 & $22.50 \%$ & Sangat Kurang \\
\hline 5. & SUM & 40 & 34 & $85.00 \%$ & Baik \\
\hline 6. & CIP & 40 & 9 & $22.50 \%$ & Sangat Kurang \\
\hline
\end{tabular}


Berdasarkan hasil-hasil tersebut, dapat diketahui kompetensi supervisi kepala sekolah di Gugus II Bima UPTD Dikpora Kecamatan Serengan secara keseluruhan masih kurang. Hal ini ditunjukkan dengan skor terendah diperoleh 0, skor tertinggi 34 (85.00\%) dari skor ideal, dan skor rata-rata sebesar 21.17 (52.92\%) dari skor ideal.

Data tingkat kompetensi supervisi kepala sekolah di Gugus II Bima UPTD Dikpora Kecamatan Serengan pada tindakan Siklus I dapat disajikan ke dalam diagram sebagai berikut:

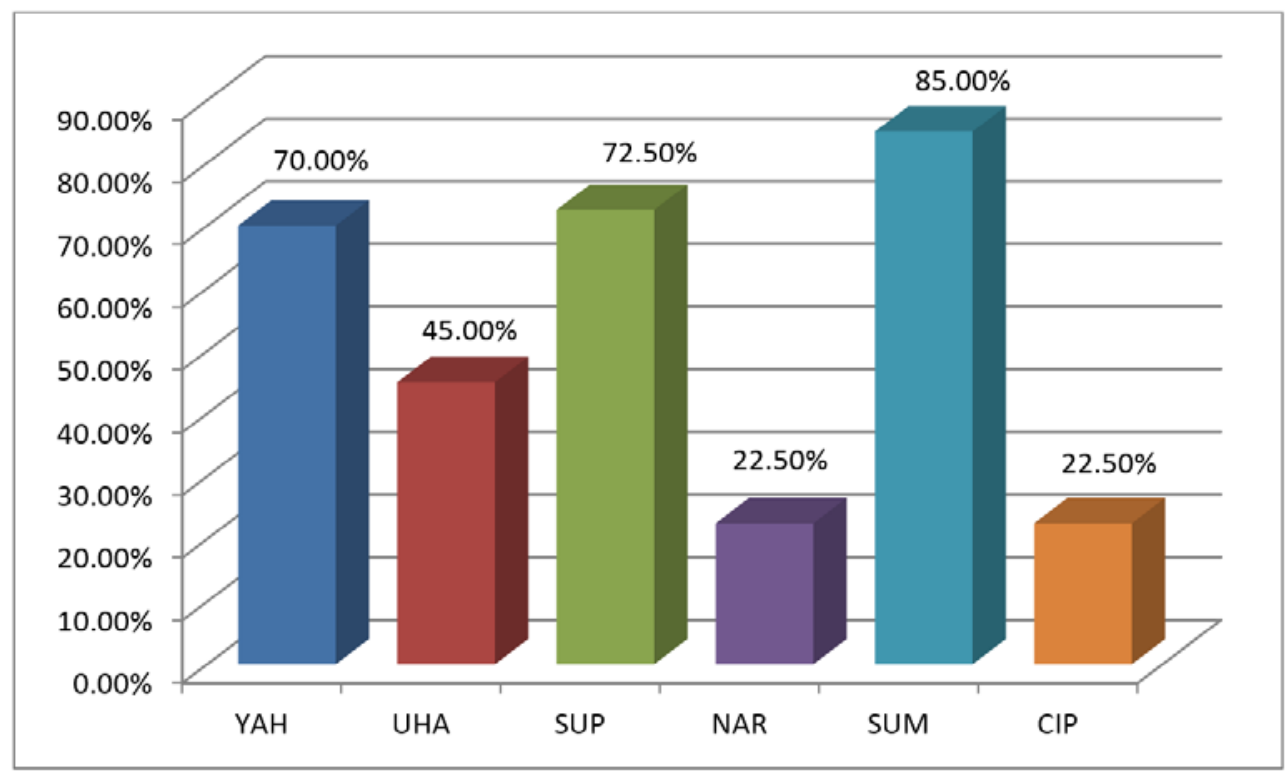

Gambar 2 Diagram Kompetensi Supervisi Kepala Sekolah Tindakan Siklus I

Hasil-hasil penilaian awal sebagaimana disajikan di atas memberikan gambaran bahwa dari 6 kepala sekolah yang ada, semuanya sudah menyusun program supervisi (100.00\%). Empat orang kepala sekolah (66.67\%) sudah menyusun rencana program supervisi dan sudah melaksanakan supervisi. Tiga orang kepala sekolah (50.00\%) sudah sudah melaksanakan program tindak lanjut supervisi.

Berdasarkan hal ini maka, pengawas melaksanakan kegiatan supervisi manajerial pada tindakan Siklus II. Perbaikan difokuskan pada pelaksanaan dan tindak lanjut supervisi.

Hasil pengamatan yang dilakukan setelah dilaksanakannya program supervisi manajerial dengan metode kelompok pada tindakan Siklus II dapat disajikan ke dalam tabel berikut.

Tabel 3

Hasil Penilaian Kompetensi Supervisi Kepala Sekolah Tindakan Siklus II

\begin{tabular}{cccccc}
\hline \multirow{2}{*}{ No. } & Inisial & \multicolumn{2}{c}{ Skor } & \multirow{2}{*}{ Ketercapaian \% } & Keterangan \\
\cline { 3 - 4 } & Subjek & Ideal & Riil & & \\
\hline 1. & YAH & 40 & 35 & $87.50 \%$ & Sangat Baik \\
2. & UHA & 40 & 29 & $72.50 \%$ & Cukup Baik \\
3. & SUP & 40 & 33 & $82.50 \%$ & Cukup Baik \\
4. & NAR & 40 & 24 & $60.00 \%$ & Cukup Baik \\
5. & SUM & 40 & 34 & $85.00 \%$ & Sangat Baik \\
6. & CIP & 40 & 22 & $55.00 \%$ & Kurang \\
\hline
\end{tabular}


Berdasarkan hasil-hasil tersebut, dapat diketahui kompetensi supervisi kepala sekolah di Gugus II Bima UPTD Dikpora Kecamatan Serengan secara keseluruhan sudah cukup baik. Hal ini ditunjukkan dengan skor terendah diperoleh 22 (55.00\%), skor tertinggi 35 (87.50\%) dari skor ideal, dan skor rata-rata sebesar 29.50 (73.75\%) dari skor ideal.

Data tingkat kompetensi supervisi kepala sekolah di Gugus II Bima UPTD Dikpora Kecamatan Serengan pada tindakan Siklus II dapat disajikan ke dalam diagram sebagai berikut:

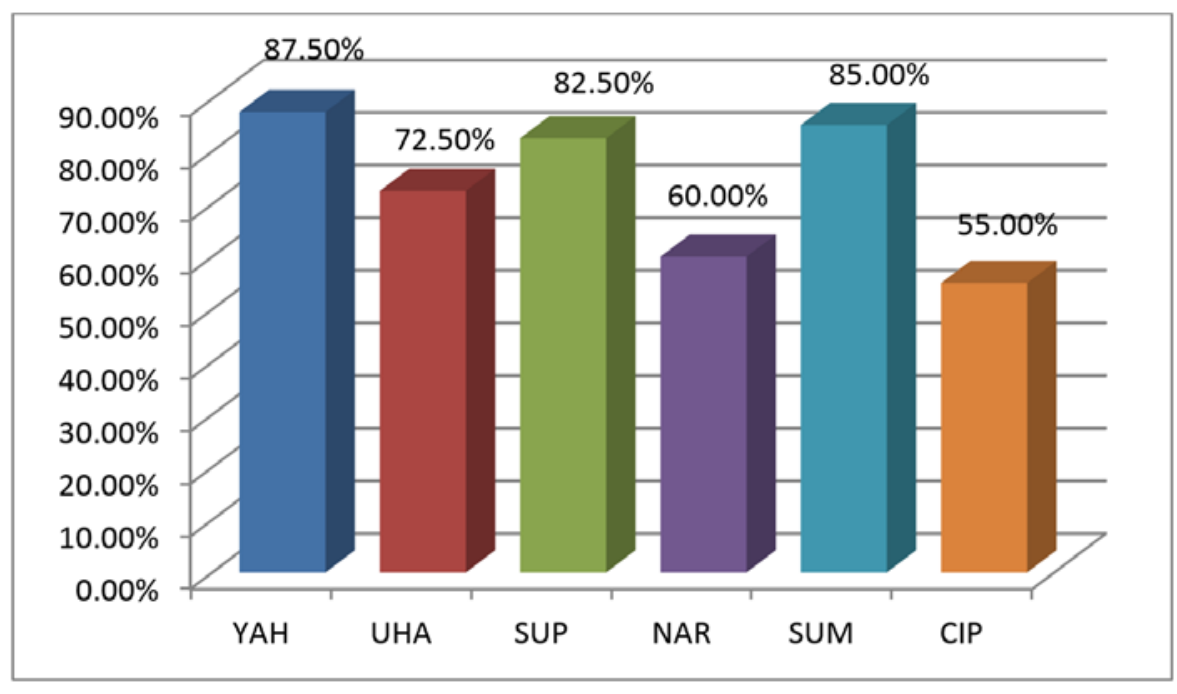

Gambar 3 Diagram Kompetensi Supervisi Kepala Sekolah Tindakan Siklus II

Hasil-hasil penilaian awal sebagaimana disajikan di atas memberikan gambaran bahwa dari 6 kepala sekolah yang ada, semuanya sudah menyusun program supervisi (100.00\%). Enam orang kepala sekolah (100.00\%) sudah menyusun rencana program supervisi dan sudah melaksanakan supervisi. Enam orang kepala sekolah (100.00\%) sudah sudah melaksanakan program tindak lanjut supervisi.

Supervisi kelompok metode direktif yang dilakukan oleh Pengawas dalam pembinaan kepala sekolah dengan materi penguatan kompetensi supervisi bagi kepala sekolah SD di Gugus II Bima di UPTD Dikpora Kecamatan Serengan Kota Surakarta dianggap berhasil dalam meningkatkan kompetensi supervisi kepala sekolah. Hal ini ditunjukkan dengan meningkatnya penguasaan kompetensi supervisi kepala sekolah pada setiap siklus tindakan.

Supervisi kelompok metode direktif yang dilakukan dengan simulasi ternyata dapat meningkatkan ketrampilan dan kompetensi kepala sekolah dalam melaksanakan pembelajaran supervisi. Pendekatan langsung adalah pendekatan terhadap masalah dengan cara langsung. Supervisor atau kepala sekolah mengadakan supervisi secara langsung, prinsip yang dilakukan adalah menjelaskan, menyajikan, mengarahkan, memberi contoh dan menguatkan. Teknik supervisi secara langsung ini bisa bersifat: (1) individual seperti kunjungan kelas, observasi kelas, percakapan pribadi, intervisitasi, menyeleksi berbagai sumber yang digunakan untuk mengajar dan melihat cara dan hasil evaluasi; (2) kelompok yaitu pendekatan yang dapat dilakukan dengan bentuk-bentuk rapat guru, panitia penyelenggaraan kegiatan sekolah, studi kelompok guru/KKG sekolah, dan workshop. Pemberian contoh yang dilakukan melalui 
bentuk simulasi dan praktek langsung akan dapat meningkatkan kompetensi kepala sekolah dalam materi yang disajikan.

Hal ini sesuai dengan konsep kepengawasan itu sendiri yang bertujuan untuk membantu guru, yaitu bahwa Dalam melaksanakan tugas pokoknya, pengawas satuan pendidikan berfungsi sebagai pengawas pendidikan baik pengawas akademik maupun pengawas manajerial (Depdiknas, 2006: 3). Sebagai pengawas akademik, pengawas satuan pendidikan bertugas membantu dan membina guru dalam meningkatkan kemampuan profesionalnya agar dapat meningkatkan mutu proses dan hasil belajar siswa. Sedangkan sebagai pengawas manajerial, pengawas satuan pendidikan bertugas membantu kepala sekolah dan seluruh staf sekolah agar dapat meningkatkan mutu penyelenggaraan pendidikan pada sekolah yang dibinanya.

Hasil penelitian menunjukkan bahwa kompetensi kepala sekolah dalam pelaksanaan pembelajaran supervisi mengalami peningkatan dibandingkan pada siklus sebelumnya. Hal ini ditunjukkan dengan meningkatnya skor hasil pengamatan yang dilakukan pada setiap siklus tindakan.

\section{SIMPULAN}

Langkah-langkah pelaksanaan supervisi manajerial guna meningkatkan kompetensi supervisi kepala sekolah di Gugus II Bima UPTD Dikpora Kecamatan Serengan Kota Surakarta tahun pelajaran 2012/2013 dilakukan sebagai berikut: supervisi manajerial dilakukan melalui prosedur berbentuk siklus yang terdiri dari tiga tahap yaitu: tahap pertemuan pendahuluan, tahap pengamatan dan tahap pertemuan balikan.

Penerapan supervisi manajerial metode kelompok dapat meningkatkan kompetensi supervisi kepala di Gugus II Bima UPTD Dikpora Kecamatan Serengan Kota Surakarta tahun pelajaran 2012/2013. Hal ini ditunjukkan dengan hasil penilaian yang mengalami peningkatan dibandingkan dengan kondisi awal. Tingkat ketercapaian pada kondisi awal baru mencapai 33.33\% dari skor ideal. Pada akhir tindakan Siklus I, tingkat ketercapaian mengalami peningkatan menjadi 52.92\% dari ideal. Kemudian pada akhir tindakan Siklus II meningkat menjadi $73.75 \%$ dari skor ideal.

\section{DAFTAR PUSTAKA}

Akhmad Sudrajat. (2007). Kompetensi Guru dan Peran Kepala Sekolah. http//:www. akhmadsudrajat.wordpress.com.

Arikunto, Suharsimi. 2010. Penelitian Tindakan: Untuk Guru, Kepala Sekolah, dan Pengawas. Jakarta: PT. Rineka Cipta.

Depdiknas. 2005. Standar Nasional Pendidikan. Jakarta: Direktorat Pendidikan Lanjutan Pertama Dirjen Dikdasmen

Hamalik, Oemar. 1993. Praktek Keguruan. Bandung Tarsito.

Mulyasa, E. 2005. Menjadi Kepala Sekolah Profesional: Dalam Konteks Menyukseskan MBS dan KBK. Bandung: PT. Remaja Rosda Karya.

Purwanto, Ngalim. 2003. Administrasi dan Supervisi Pendidikan. Bandung: PT. Remaja Rosda Karya. 
Purwanto, Ngalim. 2004. Administrasi dan Supervisi Pendidikan. Bandung: PT. Remaja Rosda Karya.

Sahertian, Piet A., 2004. Konsep Dasar \& Teknik Supervisi Pendidikan Dalam Rangka Pengembangan Sumber Daya Manusia. Jakarta: Rineka Cipta.

Slamet. 2003. Menjadi Kepala Sekolah Tangguh. Artikel. www.depdiknas.go.id diakses pada 18 Oktober 2007.

Sofiati. 2002. Pemberdayaan Pengawas TK/SD dalam Menunjang Otonomi Bidang Pendidikan di Kota Yogyakarta. Tesis. Tidak Diterbitkan. Universitas Negeri Yogyakarta.

Wiriaatmadja, Rochiati. 2006. Metode Penelitian Tindakan Kelas. Bandung: PT Remaja Rosdakarya 